\title{
Waldron, Jeremy. Political Political Theory. Essays on Institutions. Primera \\ (electrónica). Cambridge. Massachusets: Harvard University Press, 2016
}

Luis Fernando MEX ÁVILA*

\begin{abstract}
Resumen: En el presente texto se analizará la obra Political Political Theory de Jeremy Waldron. Como se explicará, el libro mencionado se conforma de distintos trabajos que el profesor neozelandés ha realizado a lo largo de su carrera así como algunos inéditos, pero que giran en torno a un mismo tema: su posición filosófica frente a los problemas normativos de las instituciones sociales contrastado con el hecho del pluralismo social. Nuestro interés es resaltar el acercamiento de reflexiones que suelen gozar de la principal atención de politólogos y científicos sociales, con estudios normativos de la filosofía política y el derecho.
\end{abstract}

\section{Desarrollo}

El presente libro es una colección de ensayos que el profesor Jeremy Waldron ha publicado a lo largo de su carrera, así como otros inéditos. El interés que tenemos por esta obra nace del novedoso enfoque que el profesor neozelandés ha desarrollado desde publicaciones como The dignity of the legislation ${ }^{1}$ hasta su libro más conocido Derechos $y$ desacuerdos ${ }^{2}$, en donde centra su atención en el hecho del pluralismo que, invariablemente, existe en las sociedades políticas actuales, y como este puede ser albergado de manera estable por sus instituciones. La idea de Waldron parece centrarse en la configuración de instancias que puedan garantizar un orden constitucional y democrático, pese a que subsistan profundas contradicciones en cuestiones de principio como los alcances de la justicia social, la libertad, etc.

En dichas obras, Waldron apuesta por una perspectiva normativa centrada en las virtudes del parlamentarismo como espacio idóneo para albergar las discusiones y posteriores decisiones sobre los derechos. A pesar de que su propuesta ha sido criticada por buenas razones ${ }^{3}$, no deja de ser llamativo el modo en el que los trabajos de Waldron han propiciado discusiones que parecían ser materia de otras disciplinas o que al menos, no gozaban de la atención de filosóficos políticos ni del derecho.

Political political theory $y^{4}$ presenta un análisis de las instituciones que albergarían los desacuerdos de una sociedad política democrática y constitucional: la oposición leal, la división

\footnotetext{
Licenciatura en Derecho y Ciencias Jurídicas en la UNID Sede Campeche; actualmente asistente de investigación en el Centro de Investigaciones Jurídicas.

1 New York: Cambridge University Press, 1999.å

2 Madrid: Marcial Pons, 2005.

3 Ver las presentadas en SAHUí, Alejandro (2017), «Desacuerdos sobre derechos: Waldron y Dworkin sobre parlamentos y tribunales.» Andamios, n³ 35, pp. 159-185.

4 Primera (electrónica). Cambridge. Massachusets: Harvard University Press, 2016.
} 
de poderes, la revisión judicial y otros temas, son analizados destacando cuestiones normativas pero que no olvidan el carácter pragmático-técnico de estos.

Nuestra apuesta es que el lector se enfoque en el hecho del desafío de concepciones y aspectos enquistados en prácticas sociales con elementos definidos, que repercuten en la justicia, la democracia y la libertad. Un ejemplo de esto se puede ver en que, como bien ha planteado el profesor de la Universidad de Nueva York, las propuestas de los filósofos en todo momento parecen dirigirse a una asamblea o parlamento, e incluso se puede razonablemente esperar que estas se ocupen en el funcionamiento de la estructura básica de la sociedad. Debido a que las propuestas mencionadas se expresan teniendo en mente su construcción y toma de decisión desde una imagen institucionalizada, parece ser que aún quedarían más preguntas por hacer además de las implicaciones de una justicia distributiva o de las alcances de la libertad igualitaria: el asunto que plantea el libro, es la problematización de presupuestos clásicos de prácticas como el rule of law o el judicial review, que a pesar de jugar en un nivel distinto a las discusiones filosóficas sobre principios, son susceptibles de mover enfoques y presupuestos dado a su talante normativamente realista.

Al ser una compilación de ensayos, no encontramos una serie de conceptos hilvanados que puedan dar cuenta de una sola materia. Más bien, lo que existe es una intuición filosófica-política que va tomando forma según las observaciones que hace el autor de distintas instituciones o prácticas sociales: en un capítulo se presentan las razones y explicaciones del porqué es necesaria una teoría política de la política; después se llega a la revisión de nociones constitucionales y una crítica a la tradición que ha imperado en ella; más adelante se encuentra una serie de escritos que invitan a repensar no sólo en las instancias de deliberación sino también la institucionalización de la propia oposición como un arreglo que prometería pluralizar a la democracia.

Como se dice en líneas arriba, esta obra no genera una teoría finalizada de la política de la política ${ }^{5}$, sino más bien asienta una suerte de agenda de investigación a tratar que puede ser tematizada en tres rubros: el constitucionalismo ${ }^{6}$, el parlamento ${ }^{7}$ y la democracia8. Las prácticas mencionadas, no sólo son consideradas como de suma importancia para las sociedades políticas, sino que probablemente son aquellas sobre las que existe mayor polémica puesto que el ejercicio del poder político halla en ellas su modus operandi. Debido a esto, nos detendremos

5 Para Waldron la política de la política, consiste en :

Even if our main preoccupation to study remains with justice, liberty, security, and equality, we still need to complement that work with and understanding of the mechanisms which these ideals -these ends of life- will be persued. This is what I mean by political political theory- theory addressing itself to politics and to the way our political institutions house and frame our disagreements about social ideals and orchestrate what is done about whatever aims we can settle on.

Traducción propia: "Incluso si nuestra principal preocupación de estudo sigue siendo la justicia, la libertad, la seguridad y la igualdad, aún necesitamos complementar ese trabajo y comprender los mecanismos con los que se persiguen estos ideales, estos fines de la vida. Esto es lo que quiero decir con la teoría política de la política: teoría que se dirige a la política y a la forma en que nuestras instituciones políticas albergan y enmarcan nuestros desacuerdos sobre los ideales sociales y orquestan lo que se hace con respecto a los objetivos que podamos alcanzar." Lo anterior en Waldron, Jeremy. Political Political Theory. Essays on Institutions. Op. Cit. Cap. I.

${ }^{6}$ Ver Capítulos II,III, IX, XI y XII en Ibídem.

7 Ver Capítulos IV, VI, VII y X en ídem.

${ }^{8}$ Capítulos V y VIII en ídem. 
en estos rubros para explicar brevemente cuáles son los aspectos que, según nuestra opinión, a Waldron le preocupan más:

1.- En cuanto al constitucionalismo, Waldron menciona su posición ante el dogmatismo imperante en esta tradición. A modo de clarificación conceptual en temas como la separación de poderes y el rule of law, característicamente tratados por los constitucionalistas, ejemplifican la postura de toda una tradición que no ha desafiado lo suficiente sus propios presupuestos. La postura escéptica mostrada a lo largo del libro, aunada al desafío constante de asuntos relacionados con la constitución, permite hallar puntos para afinar y potencializar esta corriente con miras a ir más allá de las, comúnmente, reflexiones practico-técnicas. Lo anterior se debe a los propios ejercicios conceptuales plasmados en los ensayos, ya que abren rutas hacia la dotación de cierta densidad normativa de los presupuestos mencionados. Un ejemplo de esto puede verse en lo dicho en cuanto a que el constitucionalismo no debe de ser mirado exclusivamente como un asunto que limite el poder sino que delinea, de hecho, la relación que sientan obligaciones políticas entre los ciudadanos y del gobierno con ellos; es decir, deberes tanto de limitación como de aportación.

A su vez, un punto que es importante mencionar es que a pesar de que la constitución, según Waldron, ya implica cuestiones de principio, lo que se ha olvidado es que estos no deben de ser vistos en una sola dirección. No suena descabellado, por ejemplo, que el rule of law no implica exclusivamente el anonimato o la igualdad formal, sino que esta idea también estaría relacionado con la garantía de los conocidos Derechos Sociales, Económicos y Culturales 9 .

2.-Como se ha mencionado anteriormente, Waldron se ha caracterizado por ser un férreo crítico del judicial review y, a su vez, defensor de la idea de que el parlamento es la mejor instancia para ventilar y resolver aspectos controversiales en cuanto al alcance de los derechos, así como el lugar en donde se expresa verdaderamente qué tan democrática es una sociedad política. En este momento no nos interesa revisar si tiene o no razón en este tema, sino que sus provocadoras conclusiones encaminan la discusión hacia un necesario ejercicio de autocrítica y de imaginación referente a nuevas maneras de extender las riquezas de la deliberación a un plano institucional verdaderamente plural. José Luis Martí y Roberto Gargarella, han acertado en decir que esta postura acerca a Waldron más a los teóricos de la democracia deliberativa como Habermas, que a otros de tradición minimalista ${ }^{10}$. Un ejemplo de esto, es su apuesta por el bicameralismo como fórmula parlamentaria que garantizaría una toma de decisión procesalmente justa, en contraposición de los académicos británicos que apostaban por un sistema unicameral. Como se ve, en vez de justificar su enfoque en una fundamentación que sólo insista en el sistema de contrapesos políticos, parece ser que el argumento más potente para adscribirse a este sistema, normativamente hablando, recaería en qué tan discutida (de manera razonable) pudo ser la decisión que se está tomando.

A pesar, se insiste, de que en su apuesta por una deliberación y discusión real conlleve postular algunos puntos no muy favorables para minorías históricamente discriminadas ${ }^{11}$, se debería de valorar mucho el énfasis que hace el profesor Waldron en el juego político institucionalizado más que en el papel de los tribunales. Lo anterior no se debe a que estos últimos sean una instancia que no abone a acentuar la igualdad política en las sociedades, sino que aunque existen muchos avances en cuanto a la participación de calidad e independiente de los jueces, es un hecho que siguen habiendo déficits de representación y captura del poder por parte de elites

\footnotetext{
9 Capítulo I en ídem.

10 «Estudio preliminar.» En Derechos y desacuerdos, de Jeremy Waldron, 13-44. Madrid: Marcial Pons, 2005.

${ }^{11}$ SAHuí, Alejandro. «Desacuerdos sobre derechos: Waldron y Dworkin sobre parlamentos y tribunales.». Op. Cit.
} 
económicas, culturales y políticas; mismo hecho que no parece que tenga solución solo con la participación del poder judicial. La reflexión y crítica, entonces, de los presupuestos parlamentarios, prometería revelar algunos puntos que de facto excluirían a las personas de la participación política en condiciones equitativas y, en ese sentido, se aportaría más a garantizar una toma de decisiones que a pesar de que no reúna todas las voces existentes, sí garantice un proceso de conformación en el que la discusión sea lo más democrática posible.

3.- En cuanto al tema de la democracia, no existe como tal un texto en este libro que nos hable explícitamente de ella. A pesar de esto, creemos que muchas aseveraciones se dirigen a discutir y potencializar sus frutos. Un ejemplo de ello puede ser visto en lo correspondiente a la lealtad de la oposición, en donde encontramos intuiciones sumamente interesantes acerca del papel en que los perdedores del proceso democrático, desempeñarían al tenor de un Estado constitucional. En esta sección se contrastan dos formas de "institucionalizar" a la oposición: el sistema británico y su figura del Majesty's loyal opposition ${ }^{12}$, con el estadounidense con la ocupación de cargos en la administración correspondiente. Waldron, en este punto se decanta por la primera dado el papel que esta ha desempeñado a lo largo de la historia política británica como verdadero garante de una participación política de los partidos perdedores, a su vez critica la manera estadounidense de participación de las minorías ya que termina por desdibujarse su función debido a que son incorporadas como parte de la administración gubernamental.

Nos concentramos en el tema anterior porque, a primera vista, pareciera que Waldron problematiza un principio constitucional de oposición leal, pero lo que no hay que dejar pasar desapercibido es que este tema está imbricado con los sistemas de partidos políticos y la competencia democrática. Este asunto no se expone con la intención de proponer tal o cual manera de que la oposición funcione, sino exclusivamente se visibiliza que los partidos minoritarios terminan por hacerse mudos dado a que su posibilidad de participación en el poder, al menos en el sistema estadounidense, funcionaría a suerte de regateo: te convido de la rebanada sólo si la corto como yo creo mejor. Por lo que el acotamiento del estudio de la democracia limitada a los puntos de elección de candidatos, competencia política y rendición de cuenta, parecieran ser insuficientes ya que el parlamento continuaría reflejando un déficit de participación política: Waldron nos intenta decir que el proceso democrático no termina en el momento de que gane una mayoría, sino en la manera en que las minorías son habilitadas para ser verdaderamente una oposición capaz de propiciar una rotación en el poder.

Los tres bloques anteriores en los que clasificamos los trabajos compilados, están relacionados sin duda pero, más allá de las materias que de por sí son ricas e interesantes; lo que destacamos es la manera de hacer filosofía práctica por parte de este profesor: extrae de prácticas institucionales, elementos normativos que enriquecen el ideario normativo. A su vez, potencializa y llama a la autocrítica de las disciplinas que estudian a las instituciones sociales, para mirar enfoques que puedan dar cuenta de principios y valores políticos.

Un ejemplo de lo dicho anteriormente puede ser localizado en la obra, de igual reciente publicación, del profesor Alejandro Sahuí titulado Igualdad y calidad democracia ${ }^{13}$, en donde combina intuiciones normativas con algunos aspectos de ciencia política, dando fruto a una concepción de la igualdad analíticamente útil para el régimen democrático representativo, pero potente en términos morales.

En conclusión, la lectura de Political political theory, resulta ser obligada no sólo para los interesados en la filosofía sino aquellos ocupados en temas de ciencias sociales. Insistimos en

\footnotetext{
${ }^{12}$ Podría ser entendido como "La oposición leal de su Majestad"

${ }^{13}$ Igualdad y calidad de la democracia. México: Fontamara, 2018.

CIENCIA JURÍDICA. Departamento de Derecho. División de Derecho, Política y Gobierno, Universidad de Guanajuato - Año 7, No. 13, 2018
} 
advertirles que en esta obra no hallarán una teoría terminada o conceptos finalizados, sino un viaje que despertará inquietudes y sobro todo, comentarios y criticas creativas que son un ejemplo de dialogo serio interdisciplinar. En síntesis: la política de la política, conlleva pensar en la coyuntura institucional de las sociedades políticas, y de esta manera fomentar un disfrute de libertades y derechos que a pesar de estén sujetos a discusión, estos no se ventilen a manera de un regateo o chantaje, sino de deliberación y razonamiento.

\section{Bibliografía}

Gargarella , Roberto, y José Luis Martí (2005), «Estudio preliminar.» En Derechos y desacuerdos, de Jeremy Waldron, 13-44. Madrid: Marcial Pons.

Sahuí, Alejandro (2017), «Desacuerdos sobre derechos: Waldron y Dworkin sobre parlamentos y tribunales.» Andamios, nº 35, 159-185.

(2018), Igualdad y calidad de la democracia. México: Fontamara.

Waldron, Jeremy. Derechos y desacuerdos. Madrid: Marcial Pons, 2005.

(2016), Political Political Theory. Essays on Institutions. Primera (electrónica). Cambridge. Massachusets : Harvard University Press.

(1999), The dignity of legislation. New York: Cambridge University Press. 